\title{
Konstruksi Isu Lingkungan dalam film Green Warriors: Indonesia The World's Most Polluted River
}

\author{
Raden Rahadian Firman Akbar* \\ Fakultas Ilmu Komunikasi, Universitas Islam Bandung, Indonesia. \\ *rrahadianfa@gmail.com
}

\begin{abstract}
The Citarum River has a few problems from upstream to downstream. The damage and neglect that lasted for years slowly became a threat to the surrounding community. Documentary films as a medium of mass communication in practice record and document people's lives, or raise certain values related to reality. The film Green Warriors: Indonesia The Worlds Most Polluted River tries to record and investigate the problems that occur in the Citarum Watershed. Based on this, the research questions include: (1) How is the construction of environmental issues in the film Green Warriors: Indonesia seen from the Reality Level; (2) How is the construction of environmental issues in the film Green Warriors: Indonesia seen from the Level of Representation; (3) How is the construction of environmental issues in the film Green Warriors: Indonesia seen from the Ideological Level; (4) What is the narrative structure pattern of the Citarum River problem in the film Green Warriors: Indonesia. The method used in this research is a qualitative method with John Fiske's semiotic analysis approach, through literature study and related documents relevant to the research. Based on the results of the study, it was found: (1) Construction of Environmental Issues in the film at the Reality Level focuses on depicting the community around the Citarum River; (2) Construction of the film's Environmental Issues in the Representation Level focuses on depicting the Citarum River; (3) Construction of Environmental Issues in the film at the Ideological Level focuses on capitalism in the Citarum River area; (4) The Narrative Structure Pattern for the Citarum River problem in the film shows the approach and point of view developed by the filmmaker.
\end{abstract}

Keywords: Documentary Film, Citarum River, Semiotics, Green Warriors.

Abstrak. Sungai Citarum memiliki sekelumit persoalan dari hulu hingga hilir. Kerusakan dan pembiaran yang berlangsung bertahun-tahun perlahan menjadi ancaman terhadap masyarakat sekitar. Film dokumenter sebagai media komunikasi massa dalam praktiknya merekam serta mendokumentasikan kehidupan masyarakat, ataupun mengangkat nilai-nilai tertentu yang berkaitan dengan kenyataan. Film Green Warriors: Indonesia The Worlds Most Polluted River mencoba merekam serta menyelidiki persoalan yang terjadi di Daerah Aliran Sungai (DAS) Citarum. Berdasarkan hal tersebut, maka pertanyaan penelitian ini antara lain: (1) Bagaimana konstruksi isu lingkungan dalam film Green Warriors: Indonesia dilihat dari Level Realitas; (2) Bagaimana konstruksi isu lingkungan dalam film Green Warriors: Indonesia dilihat dari Level Representasi; (3) Bagaimana konstruksi isu lingkungan dalam film Green Warriors: Indonesia dilihat dari Level Ideologi; (4) Bagaimana pola struktur naratif permasalahan Sungai Citarum dalam film Green Warriors: Indonesia. Metode yang digunakan dalam penelitian ini adalah metode kuallitatif dengan pendekatan analisis semiotika John Fiske, melalui studi pustaka serta dokumen terkait yang relevan dalam penelitian. Berdasarkan hasil penelitian ditemukan: (1) Konstruksi Isu Lingkungan film dalam Level Realitas berfokus pada penggambaran masyarakat sekitar Sungai Citarum; (2) Konstruksi Isu Lingkungan film dalam Level Representasi berfokus pada penggambaran Sungai Citarum; (3) Konstruksi Isu Lingkungan film dalam Level Ideologi berfokus pada kapitalisme pada lingkup Sungai Citarum; (4) Pola Struktur Naratif permasalahan Sungai Citarum dalam film memperlihatkan pendekatan serta sudut pandang yang dikembangkan oleh sineas.

Kata Kunci: Film Dokumenter, Sungai Citarum, Semiotika, Green Warriors. 


\section{A. Pendahuluan}

Posisi maupun peran Sungai Citarum yang sangat vital dalam berbagai aspek kehidupan, perlahan telah dirusak dan tercemar. Berbagai bentuk kerusakan serta pencemaran, meliputi aliran sungai dari hulu hingga hilir. Kerusakan tersebut ditengarai dari berbagai faktor, diantaranya perilaku yang tidak bertanggung jawab dari industri tekstil di sekitar wilayah sungai.

Seperti dilaporkan dalam Ekspedisi Citarum: Laporan Jurnalistik Kompas (2011) bahwa setiap wilayah aliran sungai memiliki permasalahan yang berbeda satu sama lain. Maka, akibat kerusakan Sungai Citarum yang terjadi, semua pihak yang memiliki kepentingan serta hidup di sekitar wilayah sungai telah dirugikan.

Sungai Citarum dalam perjalanannya telah menjadi bagian penting dalam peradaban, mulai dari pertanian, peternakan hingga perdagangan masyarakat. Akibat kerusakan aliran sungai yang terjadi, semua pihak yang memiliki kepentingan serta hidup di sekitar wilayah sungai telah dirugikan. Berangkat dari persoalan tersebut, serial Green Warriors menjadi salah satu dokumenter yang mengangkat isu mengenai Sungai Citarum.

Salah satu episode dari serial tersebut berjudul Green Warriors: Indonesia The World's Most Polluted River. Film dokumenter karya Martin Boudot ini mengangkat isu lingkungan yang melingkupi Sungai Citarum dan bagaimana dampak pencemaran yang terjadi, mulai persoalan sampah plastik hingga limbah industri tekstil di sekitar aliran Sungai Citarum. Melalui film ini, Boudot menguraikan sekelumit persoalan Sungai Citarum yang perlu dibenahi dan menjadi perhatian segera.

Film memiliki keterkaitan dengan Semiotika, khususnya dalam sebuah penelitian. Hal tersebut disampaikan oleh Sobur (2002:33) bahwa salah satu contoh permulaan tersebut yakni disertasi J.M De taal van de film (1950). Maka, peneliti akan menganalisis film Green Warriors: Indonesia The World's Most Polluted River dengan menggunakan analisis semiotika metode kualitatif dalam melihat konstruksi isu lingkungan yang dibentuk dalam permasalahan di Sungai Citarum.

Pendekatan semiotika dalam hal ini sebagai alat analisis untuk meneliti dan mengetahui maksud dari film tersebut. Selain itu, peneliti juga akan menganalisis film melalui pola struktur naratif permasalahan Sungai Citarum yang ditampilkan.

Berdasarkan pendahuluan yang telah dipaparkan sebelumnya, penelitian ini menggunakan pendekatan analisis semiotika model John Fiske dan pola struktur naratif, maka dari itu pertanyaan penelitian sebagai berikut:

1. Bagaimana konstruksi isu lingkungan dalam film Green Warriors: Indonesia dilihat dari tanda penggambaran masyarakat?

2. Bagaimana konstruksi isu lingkungan dalam film Green Warriors: Indonesia dilihat dari tanda penggambaran Sungai Citarum?

3. Bagaimana konstruksi isu lingkungan dalam film Green Warriors: Indonesia dilihat dari tanda ideologi dalam lingkup Sungai Citarum?

4. Bagaimana pola struktur naratif permasalahan Sungai Citarum dalam film Green Warriors: Indonesia The World's Most Polluted River?

\section{B. Metodologi Penelitian}

Paradigma dalam penelitian semiotika mengacu pada paradigma konstruktivis, sedangkan metode penelitian yang digunakan pada penelitian ini ialah metode penelitian kualitatif. Paradigma dan metode tersebut merupakan cara sekaligus pedoman bagaimana penelitian dilakukan.

Pada penelitian ini, peneliti melakukan analisis berupa deskripsi mengenai kasus maupun setting yang akan diteliti. Peneliti dalam hal ini, seperti yang sudah dipaparkan sebelumnya akan menggunakan analisis semiotika dengan teori dari John Fiske, yakni teori kode-kode televisi (the codes of television). Langkah-langkah yang dilakukan peneliti ialah mengumpulkan segala data dari film Green Warriors: Indonesia The World's Most Polluted River. Selain itu, peneliti juga mengumpulkan data yang berkaitan dengan konteks film yakni Sungai Citarum. 
Sobur (2002:33) menjelaskan bahwa terdapat dua hal penting dalam semiotika film yakni gambar serta suara yang mencakup tutur kata maupun musik film. Peneliti mengumpulkan tangkapan layar serta mencatat setiap narasi (subtitle) dari setiap scene yang ada dalam film tersebut. Setelah hal itu dilakukan, peneliti menyeleksi setiap scene yang sudah dikumpulkan menjadi beberapa kelompok sesuai dengan teori kode-kode televisi (the codes of television) diantaranya, level realitas, level representasi, dan level ideologi.

Selanjutnya, ketiga level tersebut yang bersumber dari film sebagai objek penelitian akan peneliti kaitkan dengan teori film, teori semiotika. Selain itu, peneliti juga dalam pembahasan pola struktur naratif akan mengaitkan dengan teori jurnalisme investigasi serta temuan data yang telah dihimpun. Maka, konstruksi isu lingkungan mengenai persoalan Sungai Citarum dapat dideskripsikan secara utuh dengan panduan dari teori the codes of television dan pola struktur naratif film.

\section{Hasil Penelitian dan Pembahasan}

Pada model analisis semiotika John Fiske terdiri dari 3 tahapan, yakni analisis level realitas, level representasi, dan level ideologi. Ketiga level tersebut peneliti gunakan untuk menjawab pertanyaan penelitian sekaligus menjadi penuntun pembahasan agar lebih terarah. Peneliti memilih empat scene dalam film pada setiap level yang akan diteliti. Maka, poin-poin penting dari ketiga level tersebut sebagai berikut.

\section{Level Realitas film Green Warriors: Indonesia}

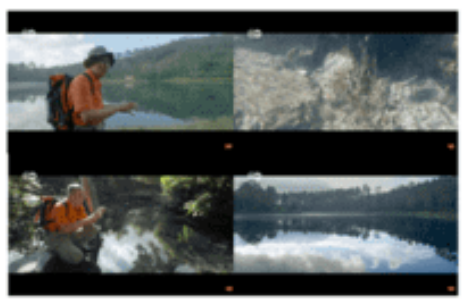

Scene no. 1 (Titi Bachtiar anggota Riset Cekungan Bandung, Situ Cisanti)

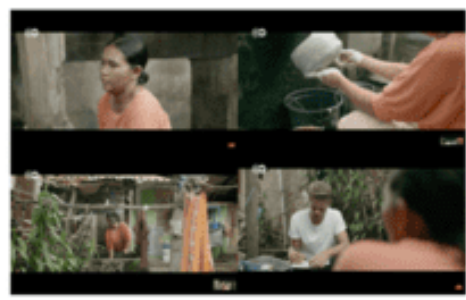

Scene no. 5

(Nour, warga sekitar aliran

Sungai

Citarum)
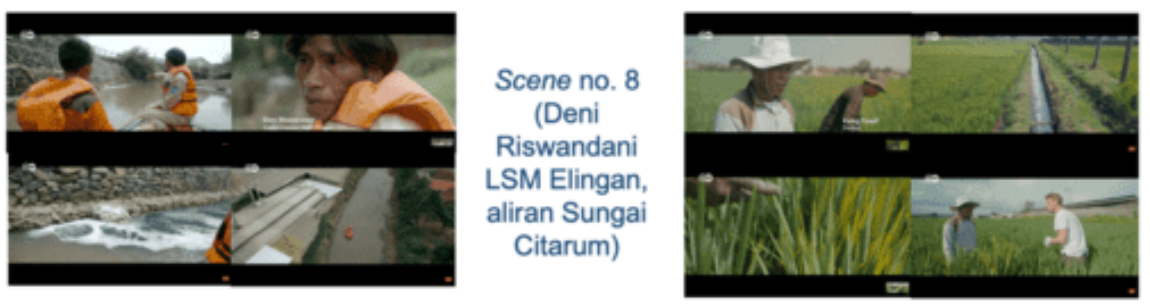

Scene no. 14

(Kang Yusuf,

lahan pertanian sekitar

aliran Sungai

Citarum)

Gambar 1.1 Kumpulan Scene Level Realitas

Kode-kode sosial pada level realitas mencakup appearance (penampilan), environment (lingkungan), serta behaviour (perilaku). Tidak semua kode-kode sebagaimana dijelaskan oleh John Fiske pada level ini peneliti gunakan. Hal ini dilakukan berdasarkan relevansi dengan film yang diteliti.

\section{Level Realitas Appearance (Penampilan)}

1. Pada kategori ini tidak ada hal yang mencolok dalam artian tak adanya rekayasa penampilan pada tokoh (masyarakat) yang muncul pada film ini dimana bersifat natural sebagaimana film dokumenter.

2. Penonton akan melihat sisi realisme dari keempat tokoh ini yang mana merupakan ciri khusus dari film dokumenter.

\section{Level Realitas Environtment (Lingkungan)}

1. Sineas menyuguhkan berbagai lokasi yang berkaitan dengan Sungai Citarum. Dimana mencakup sumber mata air Sungai, pemukiman penduduk, aliran Sungai yang tercemar serta lahan pertanian yang berdekatan dengan pabrik tekstil. 
2. Penggambaran lokasi tersebut merupakan bagian dari hubungan naratif film dengan ruang. Maksud dari hal ini ialah menunjukkan secara jelas lingkup tokoh beraktivitas.

3. Lingkungan merupakan referen atau acuan dari Sungai Citarum. Kondisi yang ditampilkan dapat pula dikatakan sebagai peristiwa yang ditandakan (encoded), terlebih melibatkan tokoh dari masyarakat sekitar.

\section{Level Realitas Behaviour (Perilaku)}

1. Penonton dapat melihat ataupun memahami mengenai Citarum melalui tokoh yang tampil dalam film. Tokoh tersebut merupakan representasi dari masyarakat yang berada di sekitar Sungai Citarum.

2. Berdasarkan naratif film yang disajikan, masyarakat tidak mempunyai kekuatan dalam menghadapi kondisi pencemaran oleh industri tekstil. Masyarakat digambarkan bukan menjadi bagian penyumbang masalah bagi Sungai Citarum.

\section{Level Representasi film Green Warriors: Indonesia}

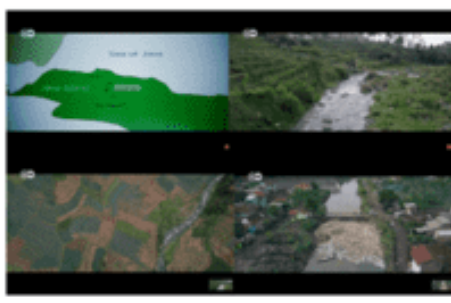

Scene no

2 (Aliran

Sungai

Citarum)

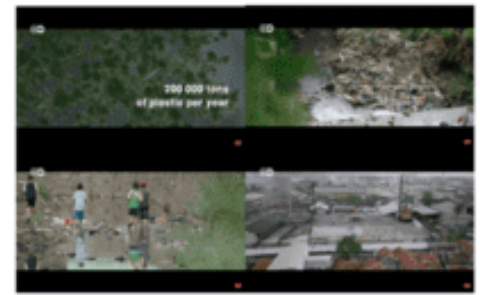

Scene no. 4

(Permasalahan

sampah aliran

Sungai

Citarum)
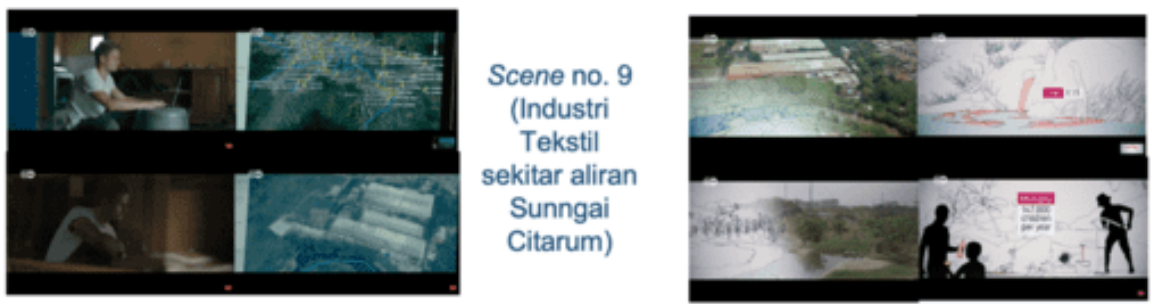

Scene no. 14 (Hasil

Penyelidikan dampak pencemaran Sugngai)

Gambar 1.2 Kumpulan Scene Level Representasi

Pada level representasi erat hubungannya dengan kode-kode teknis seperti kamera (camera), penyuntingan gambar (editing), serta Musik dan Suara (music and sound). Kode-kode tersebut peneliti pilih berdasarkan kaitan naratif film.

Level Representasi Camera (Kamera)

1. Sineas dalam praktiknya pada kategori ini selalu memiliki alasan dan tidak bersifat arbitrer. Terdapat teknik pengambilan gambar yang cukup dominan dalam penggambaran Sungai Citarum.

2. Melalui film Green Warriors: Indonesia penonton dapat melihat secara jelas penggambaran Sungai Citarum serta kaitannya dengan industri tekstil.

3. Melalui serangkaian teknik yang diterapkan pada film ini, secara tidak langsung film menggiring penonton untuk melihat industri tekstil sebagai penyebab utama kerusakan aliran Sungai Citarum.

Level Representasi Editing (Penyuntingan gambar)

1. Editing sebagai tata bahasa pada film dapat membangun naratif sebuah film agar dipahami oleh penonton. Sineas melalui hal ini tidak hanya merangkai shot yang telah diambil, namun menyematkan tanda-tanda didalamnya.

2. Secara keseluruhan, film Green Warriors: Indonesia sebagai film dokumenter tidak menyuguhkan efek khusus (special effects) yang dominan sebagaimana jenis film lain. Maka editing pada film ini lebih berorientasi pada pendukung isi maupun tema yang diusung.

3. Penonton dapat memahami Sungai Citarum serta lingkup persoalannya, khususnya 
industri tekstil. Secara khusus terdapat scene yang membahas mengenai dampak dari pencemaran tersebut dengan menggunakan tanda-tanda ikonis.

\section{Level Representasi Music and Sound (Musik dan Suara)}

1. Suara memiliki posisi yang sebanding dengan gambar, tak bisa dipungkiri bahwa suara dapat membentuk tanda-tanda. Porsi tanda dalam suara serta musik dalam setiap scene memiliki perbedaan.

2. Perpaduan narasi dan musik pada film ini sangat dominan, dimana penonton akan tergiring pada naratif yang dibangun.

3. Narator tidak hanya menjelaskan objek ataupun tindakan yang ada pada layar, namun terdapat pernyataan-pernyataan yang mengarahkan industri tekstil sebagai penyebab kerusakan aliran Sungai Citarum.

\section{Level Ideologi film Green Warriors: Indonesia}

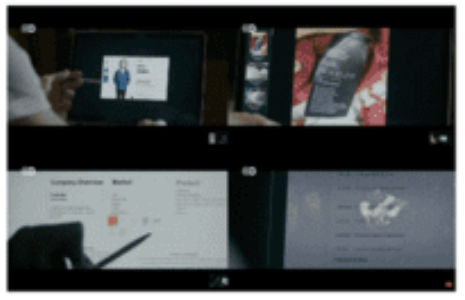

Scene no. 21 (Penelusuran produk fesyen)

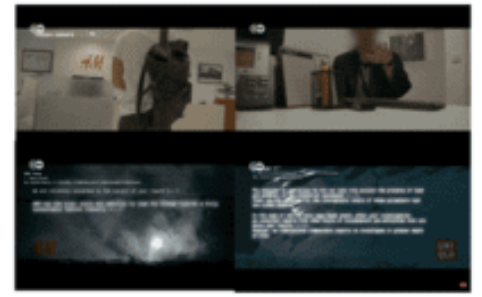

Scene no.

22

(Wawancara

dengan

pihak H\&m

dan Uniqlo)

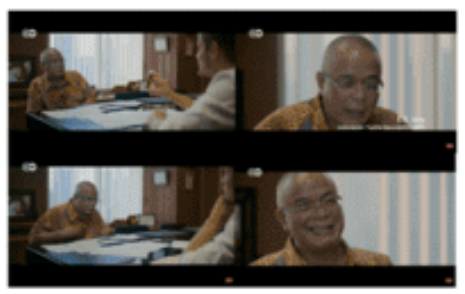

Scene no. 23

(Wawancara

dengan

pihak API)

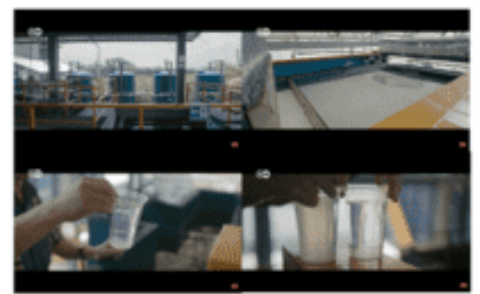

Scene no. 27

(Pengelolaan

air limbah

tekstil)

Gambar 1.3 Kumpulan Scene Level Ideologi

Pada level ini nilai ideologi berdasarkan kaitan dengan naratif film Green Warriors Indonesia ialah Capitalism (Kapitalisme). Naratif film menuntun pada ideologi kapitalisme sebagai penyebab kerusakan Sungai Citarum. Hal tersebut masih berkaitan pada level sebelumnya yakni level realitas dan level representasi.

Level Ideeologi Capitalism (Kapitalisme)

1. Secara keseluruhan melalui naratif film, salah satu hal yang disorot mengenai Kapitalisme ialah proses produksi yang mengindahkan kelestarian alam, khususnya pada Sungai Citarum. Keberadaan industri tekstil yang bermasalah tersebut tidak menjadi fokus utama dalam naratif film.

2. Secara tidak langsung, film Green Warriors: Indonesia menyajikan perspektif kepada penonton bahwa dalam produk-produk fesyen yang kita pakai terdapat proses produksi yang merusak lingkungan serta memberikan dampak kesehatan bagi masyarakat sekitarnya. Ini merupakan referen yang ditampilkan oleh sineas.

3. Merek-merek fesyen ternama yang secara langsung menghidupi keberadaan industri tekstil di sekitar Sungai Citarum tidak bisa menutup mata dengan apa yang telah terjadi.

4. Jika melihat pada komponen-kompenen ideologi, kapitalisme dalam film Green Warriors: Indonesia terdapat pertentangan antara nilai-kepentingan-pilihan. Maka, pada akhir film ditampilkan sebuah alternatif dimana perusahaan tekstil dapat mengolah limbahnya. 


\section{Pola Struktur Naratif Permasalahan Sungai Citarum dalam film Green Warriors: Indonesia}

Peneliti membuat sebuah tabel film yang mencakup scene, narasi serta durasi. Hal ini dilakukan agar mempermudah dalam melihat sebuah pola struktur naratif pada film Green Warriors: Indonesia, khususnya berkaitan dengan permasalahan Sungai Citarum. Pada pola struktur naratif film terdapat tiga tahapan yakni diantaranya: (1) Tahap Permulaan, (2) Tahap Pertengahan, (3) Tahap Penutupan. Pada tahap tersebut pula terapat poin naratif didalamnya. Maka dari itu, berikut pola struktur naratif film Green Warriors: Indonesia.

\section{Tahap Permulaan}

Aspek Ruang Waktu para pelaku

1. Perjalanan aliran Sungai Citarum meliputi hulu Sungai (Situ Cisanti) hingga berhenti pada pemukiman penduduk sekitar aliran sungai.

2. Peralihan fokus masalah dari limbah rumah tangga ke limbah industri tekstil. Masalah

1. Pengantar isu kesehatan masyarakat sekitar, berkaitan dengan penggunaan air sumur dari Sungai Citarum.

2. Pengenalan hubungan antara industri tekstil dan Sungai Citarum sekaligus permulaan

Tahap Pertengahan penyelidikan mengenai pencemaran industri tekstil oleh Martin Boudot.

\section{Konflik}

1. Tinjauan langsung Martin Boudot pada pabrik tekstil PT. Gistex.

2. Pengujian sampel air limbah PT. Gistex, Pan Asia Jaya, Lenzing. (bekerja sama dengan Lab. Eropa)

3. Pengambilan sampel kandungan padi sekitar pabrik.

\section{Konfrontasi}

1. Martin Boudot bekerjasama dengan Lab. Unpad dalam pengujian kandungan padi.

2. Martin Boudot mengambil sampel rambut pada anak-anak sekitar Sungai Citarum.

\section{Pengembangan Masalah}

1. Hasil penyelidikan mengenai kandungan air dan padi yang berkaitan dengan limbah industri tekstil.

2. Penyerahan hasil penyelidikan mengenai air pada Deni Riswandani.

\section{Tahap Penutupan}

\section{Konfrontasi Akhir}

1. Penelusuran merek-merek fesyen dunia yang memiliki kerjasama dengan pabrik tekstil sekitar Sungai Citarum.

2. Kunjungan pada merek fesyen, API (Asosiasi Perktestilan Indonesia), dan penyerahan Solusi hasil pada kandungan air \& padi pihak Kementrian.

1. Penyerahan hasil test sampel rambut pada warga sekitar.

2. Pengolahan limbah industri tekstil ramah lingkungan.

\section{Tujuan}

1. Sorotan pada produksi industri tekstil di masa mendatang serta merek-merek fesyen ternama.

Terdapat beberapa poin penting dalam kaitannya dengan pola struktur naratif permasalahan Sungai Citarum dalam film Green Warriors: Indonesia. Hal tersebut mencakup dalam kaitannya dengan jurnalisme investigatif serta temuan data yang telah dihimpun.

1. Secara keseluruhan praktik penyelidikan yang ditampilkan dalam film serupa dengan teknik proses investigative reporting secara umum yang disampaikan oleh Santana (2003), dimana memiliki karakteristik tersendiri dalam setiap langkahnya.

2. Penyelidikan dalam film bermula ketika Martin Boudot memperlihatkan data yang ia miliki mengenai keberadaan pabrik-pabrik tekstil yang berada di Sungai Citarum. Hal tersebut disampaikan dalam Santana (2003:194) sebagai paper trail (pencarian jejak dokumen). 
3. Martin Boudot selaku tokoh yang menyelidiki pencemaran, ketika bertemu dengan perwakilan API tidak mengajukan pertanyaan umum melainkan menggunakan teknik smoking-gun ataupun shotgun interview. Tipe ataupun jenis wawancara tersebut lazimnya dilakukan dalam investigasi broadcasting.

4. Pengangkatan isu mengenai hubungan antara industri tekstil dengan merek fesyen kenamaan sudah pernah di ulas dalam penelitian oleh Greenpeace berjudul Toxic Threads: Polluting Paradise (2013). Namun, pendekatan yang dilakukan tentunya memiliki perbedaan.

5. Kondisi aliran Sungai Citarum yang ditampilkan dalam film (2018) memiliki keterkaitan dengan program Citarum Harum saat ini yang melibatkan banyak pihak dan sektor.

6. Pola struktur naratif mengenai permasalahan Sungai Citarum yang hadir dalam film Green Warriors: Indonesia termasuk dalam realitas media. Model yang termasuk dalam film ini ialah model peta analog. Pada model peta analog ini dijelaskan oleh Bungin (2015:202) yakni media melakukan konstruksi terhadap realitas sosial.

\section{Kesimpulan}

Berdasarkan pembahasan dalam penelitian ini, peneliti menyimpulkan beberapa hasil penelitian sebagai berikut:

1. Kode-kode sosial pada level realitas memperlihatkan posisi masyarakat dalam kaitannya dengan persoalan Sungai Citarum dan industri tekstil yang dikembangkan oleh sineas. Secara keseluruhan masyarakat tidak memiliki kekuatan ataupun solusi dalam mengatasi hal tersebut.

2. Melalui tiga kategori kode sosial pada level representasi seperti kamera, editing, serta musik dan suara sangat dimaksimalkan oleh sineas agar penonton dapat memahami Sungai Citarum serta lingkup persoalannya.

3. Keberadaan industri tekstil serta kaitannya dengan merek-merek fesyen ternama merupakan penerapan dari nilai-nilai kapitalisme. Sorotan terhadap praktik kapitalisme tak lain karena proses produksi yang mencemari lingkungan serta berbagai kepentingan yang melingkupinya. Pada akhirnya, sineas memperlihatkan alternatif dari penyelesaian atas produksi kapitalisme itu sendiri.

4. Melalui ketiga tahapan dalam pola struktur naratif beserta aspek didalamnya, terdapat pengerucutan fokus masalah mengenai persoalan Sungai Citarum yang dibentuk oleh sineas. Seiring durasi film terdapat pendekatan lain yang dilakukan oleh sineas seperti jurnalisme investigatif maupun jurnalisme lingkungan.

\section{Acknowledge}

Terima kasih kepada seluruh pihak yang telah membantu peneliti terkhusus kedua orang tua peneliti, lalu pembimbing peneliti yakni Ibu Tia Muthiah Umar. Terima kasih juga kepada Pak Askurifai Baksin serta Satgas Citarum Harum yang telah bersedia menjadi narasumber penelitian.

\section{Daftar Pustaka}

[1] Ardianto, Elvinaro. Lukianti Komala. Siti Karlinah. 2004. Komunikasi Massa: Suatu Pengantar. Cetakan ke-5. Bandung: Simbiosa Rekatama Media.

[2] Ayawaila, Gerzon Ron dkk. 2017. Dokumenter Film dan Televisi. Jakarta: Universitas Budi Luhur.

[3] Baksin, Askurifai. 2003. Membuat Film Indie Itu Gampang. Bandung: Penerbit Katarsis.

[4] Bungin, Burhan. 2015. Konstruksi Sosial Media Massa. Cetakan ke-3. Jakarta: Prenadamedia Group.

[5] Creswell, John W. 2018. Qualitative Inquiry \& Research Design: Choosing among Five Approaches. Cetakan ke-2. Penerjemah: Ahmad Lintang Lazuardi. Yogyakarta: Pustaka Pelajar.

[6] Kompas Media Nusantara. 2011. Ekspedisi Citarum: Laporan Jurnalistik Kompas.Cetakan ke-2. Jakarta: Penerbit Buku Kompas. 
134 | Raden Rahadian Firman Akbar, et al.

[7] Lajnah Pentashihan Mushaf Al-Qur'an. 2009. Pelestarian Lingkungan Hidup. Jakarta: Badan Litbang dan Diklat Departemen Agaram RI.

[8] McQuail, Denis. 2011. McQuail's Mass Communication Theory, $6^{\text {th }}$ ed. Jilid 1. Penerjemah: Putri Iva Izzati. Jakarta: Penerbit Salemba Humanika.

[9] Moleong, Lexy J. 2019. Metodologi Penelitian Kualitatif. Cetakan ke-39. Bandung: Remaja Rosdakarya.

[10] Prasetya, Arif Budi. 2019. Analisis Semiotika dan Komunikasi. Malang: Intrans Publishing.

[11] Pratista, Himawan. 2017. Memahami Film. Cetakan ke-2. Yogyakarta: Homerian Pustaka.

[12] Santana, Septiawan. 2003. Jurnalisme Investigasi. Edisi Pertama Jakarta: Yayasan Obor Indonesia.

[13] Santana, Septiawan. 2017. Jurnalistik Kontemporer, Edisi Kedua. Jakarta: Yayasan Pustaka Obor Indonesia.

[14] Sobur, Alex. 2001. Analisis Teks Media: Suatu Pengantar untuk Analisis Wacana, Analisis Semiotik, dan Analisis Framing. Cetakan ke-8. Bandung: Remaja Rosdakarya.

[15] Sobur, Alex. "Bercengkrama dengan Semiotika," dalam Mediator Volume 3, No. 1, Tahun 2002 (hlm 33).

[16] Sobur, Alex. 2003. Semiotika Komunikasi. Cetakan ke-7. Bandung: Remaja Rosdakarya.

[17] Tim Penulis. 2013. Media dan Komunikasi Lingkungan. Bandung: Fakultas Ilmu Komunikasi Universitas Islam Bandung \& Buku Litera.

[18] Vera, Nawiroh. 2014. Semitoka dalam Riset Komunikasi. Cetakan ke-2. Jakarta: Ghalia Indonesia.

[19] Wibowo, Indiwan Seto Wahyu. 2013. Semiotika Komunikasi- Aplikasi Praktis bagi Penelitian dan Skripsi Komunikasi. Edisi kedua. Jakarta: Penerbit Mitra Wacana Media.

[20] Yenrizal. 2017. Lestarikan Bumi dengan Komunikasi Lingkungan. Yogyakarta: Penerbit Deepublish. 